\title{
Technology Standardization for Innovation: How Google Leverages an Open Digital Platform
}

\author{
Yoshiaki Fukami $^{1,2, *(\mathbb{D})}$ and Takumi Shimizu ${ }^{3}$ \\ 1 Keio Global Research Institute, Keio University, 2-15-45 Mita, Minato, Tokyo 108-8345, Japan \\ 2 Department of Management, Faculty of Economics, Gakushuin University, 1-5-1 Mejiro, Toshima, \\ Tokyo 171-8588, Japan \\ 3 Faculty of Policy Management, Keio University, 5322 Endo, Kanagawa, Fujisawa 252-0882, Japan; \\ takumis@sfc.keio.ac.jp \\ * Correspondence: yofukami@sfc.keio.ac.jp
}

Citation: Fukami, Y.; Shimizu, T. Technology Standardization for Innovation: How Google Leverages an Open Digital Platform. Information 2021, 12, 441. https://doi.org/ $10.3390 /$ info12110441

Academic Editor: Rúben Pereira

Received: 16 September 2021 Accepted: 27 September 2021 Published: 23 October 2021

Publisher's Note: MDPI stays neutral with regard to jurisdictional claims in published maps and institutional affiliations.

Copyright: (c) 2021 by the authors. Licensee MDPI, Basel, Switzerland. This article is an open access article distributed under the terms and conditions of the Creative Commons Attribution (CC BY) license (https:// creativecommons.org/licenses/by/ $4.0 /)$.

\begin{abstract}
The aim of this study is to investigate firms' strategies for developing and diffusing technology standards while maintaining a consensus with competitors in their industry. We conducted a case study of information technology (IT) standardization and analysed how Google drives the development and diffusion of HTML5 standards. Accordingly, this study sheds light on two strategic initiatives and two relational practices of standard development and diffusion. Adopting the technologies developed by other firms and forming alliances with other browser vendors are key to influencing the standardization process. Additionally, by building partnerships with developer communities, Google has accelerated the development and diffusion of the HTML5 standards. The mechanisms behind Google's standardization strategies are also discussed.
\end{abstract}

Keywords: standardization; open innovation; platform; innovation strategy; innovation trajectories; standard consortium

\section{Introduction}

Innovation in any industry involves frequent collaboration and coordination with diversified stakeholders among the suppliers, complementors, and consumers in an industry's ecosystem. A standard, which determines the interfaces and specifications of how the modules of a system cooperate with others in order to realize compatibility, is an enabler and promoter of such innovation activities [1]. Compatibility standards play an essential role in creating new services and products that realize industry evolution [2]. For example, any service designed with the Internet of Things (IoT) works only in concert among multiple components on the internet, entailing specifications adopted by whole industries. Since technological standards have substantial influences on innovation and technological trajectories in an industry, they unavoidably affect the strategies and performance of firms [3,4]. Thus, how companies define and support technological standards is necessary for their innovative activities and results.

Scholars have attempted to understand how technological standards influence industries (The authors had also conducted a preliminary analysis on information technology standardization before [5], and this manuscript is a substantial revision of that study.). The standard developing process can be categorized into three fashions according to which organizations lead standardization: government-based, market-based, and committeebased standardization [1]. These methods of governance are not mutually exclusive but entangled; organizations develop a consortium to reach a consensus among multiple stakeholders within industries while they compete mutually. As a result, the standard setting procedure consists not only in technical debates but also strategic and political competitions [6,7]. Diverse actors collaborate and negotiate their perspectives based on their own backgrounds $[8,9]$. Moreover, the diffusion of standards is well accelerated by network 
effects [10], costs associated with adoption [11], benefits from adopting standards [12,13], and coordination among participants [14]. However, these two streams of literature, standard development and diffusion, are rarely discussed together. Although there are a few exceptions [15-17], most previous studies treat standard development and diffusion as discrete activities and have given little attention to the mutual association of development and diffusion procedures. Even among researchers who analyse the interaction between standard development and diffusion, the most essential focus is on the standard setting procedures itself rather than on strategic actors and their practices. Therefore, the strategies of firms in standard developing procedures, which involve development and diffusion together, are mostly unidentified.

This study examines how a firm strategically contributes to the development of specifications of technology standards and makes them diffused. Firms align this standardization effort with their innovation trajectories and reach a consensus among stakeholders with conflicting interests. To approach this issue, we conducted a three-year longitudinal field study of standardization of web technology. We have analysed mainly the way that Google leads the standardizing activities of HTML5 and promotion for developers of outside of the standard developing organizations. HTML5 is the fifth major version of hypertext markup language, with APIs and other new functions, which is an essential technology standard in the web industry, to favour Google's innovation trajectories within a standard developing organization for the Web; the Worldwide Web Consortium (W3C). HTML5 has been developed as a non-proprietary sociotechnical platform [18] through open collaborative activities in and outside of the standard developing organization. Moreover, Google and Apple established a web-based mobile platform through the development of HTML5, respectively [19]. Our qualitative analysis reveals that Google has adopted two strategic initiatives (i.e., integrating outside technologies and avoiding the monetization of technologies) and two relational practices (i.e., forming alliances with browser vendors and engaging developer communities) to create an open platform for web applications on HTML5 through competition and coordination with other stakeholders with different technological and business backgrounds, such as Microsoft and IBM. Alongside developing technology standards through coordination in the standard setting organization, Google had also distributed an open-source add-on program for browsers (that provided functions to be implemented to the HTML5 specifications), encouraged consumers to support for HTML5 and advocated proposed specifications with which third-party developers can implement services. Google has also integrated outside technologies, regardless of who invented them, and has refrained from making profit with monetizing web applications based on the HTML5 standards directly. Therefore, it has induced many application developers and browser vendors as (unofficial) contributors to develop web services that are compatible with Google's open web application strategy. That is, the development and diffusion of Google's HTML5 specifications were driven by the compatible service development by engineer communities and the diffusion of HTML5 specifications among other browser makers. This attempt has led to a consensus among stakeholders in the industry and, finally, to the official recommendation of HTML5. Eventually, this research contributes to an understanding of the mutual entanglement of standard development and diffusion, while providing insights into how firms can strategically define innovation trajectories in their business through standardization.

This paper is structured as follows: The second section illustrates the literature on standard development and diffusion and clarifies a research gap and problem regarding the bridge between these two aspects of standardization. We then explain the context of our research, our methods of data collection, and our analytical approach. In the fourth section, we explain our empirical findings by the detailed case of Google and HTML5. In the fifth section, we examine the theoretical mechanisms behind standard setting and promotion based on our observational findings and the literature. Finally, the paper discusses our theoretical contributions, practical implications, and some directions for future research. 


\section{Theoretical Background}

In the field of information systems, information technology (IT) standards can be defined as "sets of specifications for communicating or performing actions that ensure that various technologies or products that implement certain specifications are compatible [16] p. 1208". Our research is based on the process view of IT standard setting (i.e., IT standardization). IT standardization is not straightforwardly an activity to seek practical specifications. It contains a concurrence of proposed specifications, with reaching consensus among stakeholders with conflicting interests. Thus, standardization activities form a part of sociotechnical systems [20]. Excessive selfish behaviours during standard setting process can cause self-destruction [6]. Therefore, proponents of a specification need to principally balance their own interests with those of the whole industry that they belong to and society as a whole. Standards involve both benefits and costs. A standard reduces transaction costs, realizes economies of scale [21] and encourages innovation in markets with high uncertainty [3]. Moreover, standards development includes coordination costs among diversified participants with conflicting interests, possibly resulting in delays in standardization [22]. If the proposed specifications are not diffused, their benefits cannot be obtained, whether accepted as standards or not. IT standardization literature can be divided into two main research streams: standard development and diffusion.

Preceding research have paid comparatively little attention to the standard setting process, compared to the diffusion process $[16,23]$. There is a fundamental on the consensus in the literature, pointing to the fact that IT standardization is not only a technological issue but also involves social and political aspects $[6,7,24,25]$. In many cases, firm participation in private consortia or alliances primarily affects the standardization process [26,27]. Institutional factors, such as the governance of standard setting organizations, affect how participating actors coordinate their different perspectives to develop standards [9]. As diverse stakeholders who compete in a market participate in standardization activities, the dynamics among these participants play an important role in the process [7]. Therefore, the participants involved in a standard development process need to cooperate with their competitors [6].

The previous research on standard diffusion in IT has identified some key drivers. The costs and benefits associated with an adoption of standards play significant roles in standard diffusion. When the switching costs associated with shifting from one standard to another are high, firms will typically decide not to adopt new standards [11]. Firms will also consider how much benefit they can achieve from adopting a particular standard [11,13]. As adopting standards leads to compatibility and cooperation opportunities among adopters of standards, firms carefully choose a standard to achieve sufficient collaboration gains [12]. Network externality, which is closely related to the benefits of standards, is another notable factor $[10,11]$. This suggests a positive association between the size of a network (i.e., the number of adopters) and the benefits of adopting a network technology [28]. The more adopters an IT standard attracts, the more adopters that can benefit from the standard. Therefore, this IT standard will attract additional new adopters and its implementation will continue to expand. For a committee- or government-based standardization [1], deliberate coordination also plays a key role in the processes of IT standard diffusion. The centralized coordination and mobilization of related actors by consortia or government bodies can ensure the adoption and convergence of a single standard [14,29].

A real agenda emphasized in the standardization research is that there are sometimes competitions among standardization activities for similar functions. The development and diffusion of standards are mutually constitutive and are linked as collective dilemmas [8,30]. Nonetheless, most previous research into standards has been conducted with the view to treat development and dissemination as separate issues, with limited focus on the intertwined nature of standard setting activities. Even those research that collectively analyses the development and diffusion (e.g., [15]) principally focus on the standardization process itself and do not extend scope of the analysis to strategy on that participants act based. A rare exception is the work of Hanseth and Bygstad [31], which identifies three 
standardization strategies (i.e., anticipatory standardization, integrated solutions, and flexible generification) and how they perform as healthcare-related standards that are mainly lead by governments and local communities. In addition, Wen et al. [17] depict factors that can help firms contribute to standard development (i.e., having central positions in their standardization network) and can increase the rate of new product introduction, based on a given standard. Although these studies partially describe both standard development and diffusion, there are still areas that need to be elucidated regarding their interplay [16]. Therefore, we have not yet reached a clear understanding of the firm strategies that involve both standard development and diffusion when a firm needs to collaborate and compete simultaneously with heterogeneous actors in a particular field.

\section{Materials and Methods}

\subsection{Research Setting}

We employed a case study approach involving extensive interviews and field observations of a standard development and diffusion processes in the Internet industry. We studied the process of standardization of hypertext markup language at the World Wide Web consortium and examined how Google shaped the standardization process to favour its innovation trajectories. The inductive case study approach was suitable for our research since we particularly focused on an undertheorized, emerging phenomenon [32,33].

Standardization is a collective activity involving multiple stakeholders. Many standard setting processes are unfolded beyond official communication platforms of standardization organizations. For instance, engineers who belong to participating companies of the W3C and independent engineers usually discuss developing and improving specifications. HTML5 development is thus a typical example of remote collaborative efforts [34]: the process of standard development and diffusion is influenced by multiple stakeholders outside the standardization consortium. The previous version of HTML was created as simple "markup" languages which compose documents with links to other documents. However, the HTML5 is not only a markup language for stable documents. It also serves as a foundation for services with application programming interfaces (APIs) and useful functions. It plays the role of a platform for applications. Stakeholders collaborating in standard-setting processes have conflicts of interests. Hence, the process of standard development of HTML5 can also be considered as an example of co-opetition [35,36], a case that encompassed Google, Apple, and Microsoft. Moreover, the success of Google in HTML5 standardization can be attributed to consensus building with other W3C members while obtaining support from developers outside the W3C.

\subsection{Data}

Field observations were conducted by the first author at the Japan office of W3C from April 2010 to March 2013, which leads to the detailed documentation of the process of HTML5 standardization. During the observation period, the author attended numerous W3C department meetings, headquarter staff meetings, and plenary meetings and had formal and informal conversations with W3C staff and members of participating organizations. As a result, we obtained access to the member-only listservs of the W3C working groups, technical documents, meeting resources and minutes, and PR materials such as press releases. Through these observations of $\mathrm{W} 3 \mathrm{C}$ meetings and communications, we obtained a holistic and detailed understanding of HTML5 standardization. We also conducted formal interviews with W3C staff and engineers at Google and with independent software developers who were part of the HTML5 community. These interviews enabled us to understand the context of the standard development and diffusion process in the case of HTML5, as well as how Google and other stakeholders engaged with this process.

In addition, we also gathered Google's actions and related stakeholders' responses by collecting news articles, press releases, and official documents published by W3C, Google, and other stakeholders. Here, the relevant stakeholders were not only W3C participating members and organizations. Community interactions among software developers of 
member institutions and independent developers also influenced the process of standard development and diffusion. Furthermore, we gathered the data posted on the web, such as social media and blogs, which were sometimes featured in the news articles. Table 1 summarizes the main data sources.

Table 1. Main Data Sources.

\begin{tabular}{|c|c|c|}
\hline & Quantity & Detail \\
\hline Formal semi-structured interviews & $\begin{array}{c}13 \text { people } \\
\text { (120 min per interview on average) }\end{array}$ & W3C staff, 3; Google staff, 5; developers, 5 \\
\hline Meeting observation & 57 meetings & $\begin{array}{l}\text { W3C department meeting, 50; W3C headquarter } \\
\text { staff meeting, 4; W3C plenary meeting, } 3 \\
\text { W3C internship observation (May 2009-March }\end{array}$ \\
\hline Other field observations & 4 years of observations & $\begin{array}{l}\text { 2013), HTML5j.org meeting, 20; engage with } \\
\text { developer communities }\end{array}$ \\
\hline W3C official published documents & 51 documents & $\begin{array}{l}\text { W3C specifications; WHATWG specifications; } \\
\text { press release }\end{array}$ \\
\hline W3C Internal communications & 31 listservs & $\begin{array}{l}\text { W3C member-only listserv; W3C internal meeting } \\
\text { minutes; W3C public listserv }\end{array}$ \\
\hline Media articles & 28 documents & Articles of Google and other stakeholders; blogs \\
\hline
\end{tabular}

\subsection{Analytical Approach}

Using an inductive approach, this study focused on analysing the standardization process of HTML5 and how Google acted in this process [32]. Firstly, based on the collected data, including field observations, interviews, internal documents and communications, and publicly available resources (e.g., press release and media articles), we developed a chronology of the standardization process of HTML5 and identified key activities and events of stakeholders during this period. Table 2 succinctly summarizes the major events of this standardization process. Through this process, we obtained a clear understanding of how HTML5 was developed and diffused in the web industry and of the key actions taken by Google to realize this process.

Secondly, we analysed how Google acted strategically and mobilized its resources and stakeholders to influence the process of HTML5 standardization in a favourable way; a process involving all the related materials mentioned above. As we developed the chronology and deepened our understanding of Google's strategic actions, we determined the theoretical constructs and themes in terms of how Google strategically shaped this standardization process. After we analysed the standardization process as a whole and key strategic actions made by Google, we conducted the triangulation by analysing various data and materials by key stakeholders in this standard setting process, which included field observations, articles, press releases, interview articles, blog entries, and social media posts. In addition, we continuously iterated between theories to the data to develop our theoretical constructs and deepen our understanding of HTML5 development and diffusion. As a result of this inductive analysis, we identified two theoretical dimensions of findings (i.e., strategic initiatives and relational practices) and two specific themes for each dimension. Moreover, we discussed how these initiatives and practices related to HTML5 standardization activities. Below, the arguments in the Discussion Section aim to describe the mechanisms by which Google managed this intertwined nature of standard development and diffusion. Moreover, we develop these insights in the remainder of this paper. 
Table 2. Event Chronology.

\begin{tabular}{|c|c|}
\hline Year & Major Events \\
\hline \multirow{2}{*}{1999} & W3C publishes a working draft of the Modularization of XHTML (a new version of HTML). \\
\hline & W3C updates the standardization process document (adopting implementation-oriented policy). \\
\hline 2001 & Paul Buchheit starts the project of Gmail development at Google. \\
\hline \multirow{2}{*}{2003} & Ian Hickson (Opera) submits "XHTML Module: Extensions to Form Controls" to the W3C. \\
\hline & W3C adopts the patent-free policy. \\
\hline \multirow{3}{*}{2004} & Google launches the Gmail (the first real-time Web application in the history). \\
\hline & $\begin{array}{l}\text { W3C holds the Workshop on Web Applications and Compound Documents. At the workshop, the specification } \\
\text { proposal of the next generation HTML by Opera and Apple is rejected. }\end{array}$ \\
\hline & $\begin{array}{l}\text { The WHATWG is established by engineers at Apple, Opera, and Mozilla as an open community for Web engineers. } \\
\text { WHATWG publishes the Web Forms } 2.0 \text { (an extension to the HTML functions). The Editor (Ian Hickson) plans to } \\
\text { incorporate this to the W3C standardization process. }\end{array}$ \\
\hline \multirow{4}{*}{2005} & $\begin{array}{l}\text { Google hires Goodger and Fisher (Mozilla's lead engineers). Google supports the development of Mozilla Firefox. } \\
\text { Google launches the Google Maps (a key Web application to engage with other application developers). }\end{array}$ \\
\hline & Google acquires Android Inc. (developing an operating system for mobile devices). \\
\hline & WHATWG publishes the working draft of Web Application 1.0 (features to HTML). \\
\hline & Google hires Ian Hickson (Editor of Web Forms 2.0 and an engineer at Opera). \\
\hline \multirow{3}{*}{2006} & WHATWG starts the specification development of HTML5. \\
\hline & Google launches Google Docs and Spreadsheets (strengthens its Web application offerings). \\
\hline & W3C starts the new working group (the HTML5 WG) with Google, Apple, Mozilla, and Opera. \\
\hline \multirow{4}{*}{2007} & Microsoft joins the HTML5 WG and sends Chris Wilson as a co-chair of the WG. \\
\hline & Mozilla, Opera, and Apple collectively proposes the WHATWG specifications as a draft of HTML5 specifications. \\
\hline & $\begin{array}{l}\text { Microsoft launches the Silverlight (a multi-media native application, not Web application). } \\
\text { W3C decides to adopt the WHATWG specifications as the draft of HTML5. }\end{array}$ \\
\hline & Google launches Gears version 0.1 (add-on software for Web applications). \\
\hline \multirow{4}{*}{2008} & The first working draft of HTML5 is published by W3C. (Editors: Hickson (Google) and Hyatt (Apple).) \\
\hline & Google starts the API Expert Program for application developers. \\
\hline & Google launches Google Chrome Beta. \\
\hline & Google heavily promotes HTML5 at the conference (Google I/O). \\
\hline \multirow{3}{*}{2009} & A HTML5 developer community (HTML5-developers-jp) is founded with the support of Google. \\
\hline & Microsoft starts to join the development of HTML5 specifications. \\
\hline & Microsoft asks users to update the older version of Internet Explorer (IE6) to accommodate the HTML5. \\
\hline \multirow{3}{*}{2010} & Microsoft launches the Internet Explorer 9 Public Beta (HTML5-compatible). \\
\hline & Steve Ballmer (CEO of Microsoft) makes a keynote speech on HTML5. \\
\hline & $\begin{array}{l}\text { Google hires key software engineers to promote HTML5 development (Silvia Pfeiffer at Mozilla and Chris Willson } \\
\text { at Microsoft). }\end{array}$ \\
\hline 2011 & All the main Web browsers (including Internet Explorer 9) becomes HTML5-compatible. \\
\hline 2011 & The HTML5 WG calls for broad review of HTML5 (last call for working draft). \\
\hline 2012 & W3C announces the completion of HTML5 development and moves to implementation and testing. \\
\hline 2014 & W3C publishes an official recommendation of HTML5. \\
\hline
\end{tabular}

\section{Results}

Google created a new service and business model, successfully based on web applications, by innovating through the standardization efforts. Table 2 summarizes major events during the standardization process of HTML5. At Google's annual conference for software developers, called Google I/O, Google announced its strategy of web standards as one of its key components to develop its own technologies, such as blink, an HTML-rendering engine for web browsers and other products and specifications [37]. After this symbolic event, Google accelerated its strategic engagement with the standardization process of web browsers and applications [38]. Any standard that enables web applications is collectively developed. The main factors of a successful standard include collective support for the proposed standards from related actors and efforts of consensus building regarding the standards (here, HTML5). Google achieved such success by adopting two strategic initiatives (how it integrates outside technologies and avoids the monetization of technologies) and engaging two relational practices (how it forms alliances with browser vendors and engages with developer communities). 


\subsection{Integrating Outside Technologies}

Google successfully developed an open platform for web applications by adopting existing proposals developed by other firms. HTML5 is a set of specifications that integrates a plurality of technologies to execute a web application. The "XHTML module", which was renamed "Web Forms 2.0", and "Web Applications 1.0" was later consolidated into HTML5. The existing proposals were developed by Ian Hickson, an engineer at Opera Software (a Norwegian browser vendor) who had previously worked at Netscape, a US-based browser vendor. He was employed and appointed by Google as a director of standard setting activities to refine these prototype specifications. Thus, in September 2003, Google proposed the "XHTML Module: Extensions to Form Controls" to the W3C Forms Working Group (WG). "Web Form" or "HTML form" is an element of web pages that permits users to input various features, such as textboxes, checkboxes, and submit buttons. Hickson's proposal was, therefore, an attempt to add functions of applications to web technology standards shared across industries. Compared to Netscape's and Sun Microsystems' attempts to apply JavaScript to their products, Hickson's proposal to the W3C, an open standard-setting organization, aimed to compel all web browser vendors to apply the proposed functions to their products. The "XHTML Module: Extensions to Form Controls" proposal in September 2003 was, then, the first attempt to transform HTML into a platform for web applications. To collectively develop this proposal, software engineers at Apple, Mozilla, and Opera formed an open developer community called the "Web Hypertext Application Technology Working Group" (WHATWG). Ian Hickson's initial proposal was revised and renamed "Web Forms 2.0" by the WHATWG (Hickson was the editor) and offered to the Workshop on Web Applications and Compound Documents, which was hosted in June 2004 by Opera Software and the Mozilla Foundation.

There were two options for Google to expand its business to web application-related services. The first option was to develop proprietary specifications and implement them exclusively on Google's own web browser. The second option was to adopt the specifications proposed by Hickson and the WHATWG and to cooperate with them to collectively develop the HTML5 standards. Both options had pros and cons. On the one hand, the proprietary strategy involved fewer coordination costs and a greater appropriability of the profits generated by the specifications. In this case, Google would face market competition with other browser vendors and OS vendors. On the other hand, technology firms can reduce development costs and complement their technical expertise by adopting outside technologies. However, when adopting outside technologies and cooperating with other vendors, no party can profit from the intellectual properties proposed by the standards since the W3C has adopted a royalty-free policy. Of these two options, Google chose the second and succeeded in developing and diffusing advanced web applications by shaping technology standards in a direction favourable to itself.

Google's first attempt to develop and expand its products and services as web applications started in 1999. This followed the hiring of Paul Buchheit, who initiated the development of Gmail in August 2001 and launched the popular mail service on 1 April 2004. Thereafter, several other key web applications, such as Maps and Spreadsheet, were launched to develop Google's web application-based ecosystem. The functions of these web applications were limited by web browsers because the available versions of browsers provided an interface for the services. Thus, to fully exploit the potential of web applications, the functions and capacities of web browsers needed to be improved. Therefore, with the aim of developing a web application-based ecosystem, Larry Page and Sergey Brin (the cofounders of Google) proposed creating a Google web browser to Eric Schmidt (the executive chairman of Google) in March 2001 (the year Schmidt joined the firm). Prior to the launch of their own web browser in March 2001, Google had supported existing browser vendors to develop and implement functions for web applications. However, Google's web browser strategy did not involve the vertical integration of applications and web browsers. Instead, Google encouraged all browser vendors to move towards an open digital platform supporting web applications, which later led to the development of 
HTML5. After the publication of the first draft of HTML5 at the W3C, Google's Chrome browser was released in 2008. This browser was HTML5 compatible and developed with outside technologies, such as Apple's webkit browser engine and Mozilla's open-source technologies. As Google did not have browser technologies at that time, it needed to adopt outside technologies and hire talents from other browser vendors (these details are discussed in Section 4.3). This strategic initiative, therefore, enabled Google to shape the HTML5 standardization process to favour its innovation trajectories, which prioritized an open digital platform for web applications.

\subsection{Avoiding the Monetization of Technologies}

The W3C's web standards include a royalty-free policy. In other words, firms cannot receive revenue from patenting the technical specifications that they propose to the $\mathrm{W} 3 \mathrm{C}$ as standards. Thus, Google chose an intellectual property (IP) strategy that generates no profit from the core components of web applications. This IP strategy was adopted not only by Google but also by other browser vendors who have developed HTML5compatible browsers that support web applications. Accordingly, this strategic initiative enabled Google to diffuse its technical specifications and increase its network effects among standard adopters.

There were several strategic actions enabled by this initiative (avoiding the monetization of technologies). Ben Goodger and Darin Fisher, who had worked at Mozilla as developers of the Firefox browser, joined Google in January 2005. They continued to work for Firefox development at Google, since Google supported open-source software (OSS) development, especially for web browser and web application-related products. In line with its support for a nonmonetized OSS, Google also released the Gears browser extension program, allowing web applications to run offline, as open-source software in 2007. Furthermore, Google wanted to promote its technologies through standardization rather than keeping them closed and proprietary to obtain revenue from them. Hence, the Gears program was announced on the first Google Developer Day, held in Sydney in 2007. Google promoted Gears and its functions, not to end users, but to web browser vendors and application developers. After Gears gained popularity among developers, Google decided to stop developing Gears technologies and instead incorporated them into the open technology standards of HTML5. As a result, it succeeded in assembling developers' interests in web applications and the functions of HTML5 by promoting Gears. Developers who recognized the benefits of HTML5 then began to deride Microsoft's policy on the lack of implementation of HTML5 in its web browser, Internet Explorer. Due the pressure from HTML5 supporters, Microsoft adopted HTML5 and made a promotion campaign for its users to update their browser to the latest Internet Explorer with HTML5 functions.

Google newly developed the functions related to Gears with HTML5 in March 2008. After three months at a conference for software developers, called Google I/O 2008, Aaron Boodman, who is technical lead of the Gears project, made a presentation titled "HTML5, Brought to You by Gears."

HTML5 is a new set of proposed extensions to HTML that radically improve the capabilities of web applications. However, without implementations in a majority of browsers, these proposals remain just that, and out of reach for developers. The Gears mission is to begin implementing these APIs today, across as many browsers as possible, as quickly as possible. In this talk, I'll explain why we are doing this, what our motives are, and show how implementing web standards is good for Google and good for the web. [39]

An engineering director, Linus Upson, at Google, gave the following comments in a specialized journal magazine in December 2009:

Yes, we are not driving forward in any meaningful way [on Gears]. We're very focused on moving HTML5 forward, and that's where we're putting all of our energy. [40]

Mr. Upson finished the development of Gears and announced that Google would focus its resources on the development of HTML5. Thereafter, Google officially declared 
the end of the Gears project in March 2011. Staff who engaged with the Gears project stated the following:

With all (application caches, IndexedDB API, File API, geolocation, notifications, and web worker APIs) this now available in HTML5, it's finally time to say goodbye to Gears. Now that these features have all been adopted by browsers and have official W3C specs, they are available to more developers than we could have reached with Gears alone. [41]

In short, Google summarized how it had created needs and demands for web applications and compelled software developers to realize the necessity of technology standards and open digital platforms and web applications. Google developed the features of Gears to be adopted as web industry-wide technology standards, which were then incorporated into HTML5. Providing free HTML5-compatible browsers encouraged end users to recognize the benefits of these specifications. Thus, Google succeeded in implementing HTML5compatible functions into many web browsers at no cost to their vendors and gained support for the HTML5 by end users and engineers while avoiding the monetization of its technologies.

\subsection{Forming Alliances with Browser Vendors}

Google strategically diffused and developed the standard of HTML5 by forming alliances with other browser developers (i.e., Apple, Mozilla, and Opera) through collective activities at the W3C. Google adopted the proposal developed by Mozilla and Opera, hired software developers from these browser vendors, and engaged in a collaborative diffusion of HTML5.

Ian Hickson started the development and diffusion of HTML5 as an individual activity in Opera, and the browser team at Apple and Mozilla started to support Hickson's actions. Mozilla and Opera submitted a position paper together to the "Workshop on Web Applications and Compound Documents" which was held on July 2004. The features proposed were as follows:

(1) backward compatibility with a clear migration path;

(2) well-defined error handling;

(3) no exposure of users to authoring errors;

(4) open process [42].

W3C, however, rejected this proposal because it had started to standardize XHTML as the next version of HTML. W3C, Tim Berners-Lee-as a thought leader of web standards—and IBM initially supported the development of XTHML. XHTML was an upgraded HTML with XML technology that was not compatible with the latest version of HTML in 2004. Thus, it did not meet the needs of website developers or end users. However, XHTML was supported by W3C team staff, including Berners-Lee and IBM, the firm that had developed Generalized Markup Language (GML; the ancestral specifications of HTML).

Since $\mathrm{W} 3 \mathrm{C}$ is not a governmental agency that has regulatory power and control, it is not able to force multiple stakeholders to use standards published by the W3C. If a majority of browser vendors adopts and implements W3C standards, the standards proposed by W3C will be diffused. Therefore, Google sought to develop alliances with other key browser vendors in order to diffuse its platforms for web applications. As mentioned above, the development of Firefox was supported by Google, which hired browser software developers who contribute to the Firefox. In addition to that, Google also hired Ian Hickson, who originally proposed an initial version of HTML5. With the help of Google, Mozilla and Opera re-submitted their proposal for "Web Forms 2.0" to the W3C on February 7, 2005 and, eventually, W3C accepted it. After this proposal, browser vendors competed with each other in the W3C. Ultimately, the W3C had two candidates for the new edition of HTML. Browser vendors implemented HTML5 functions into their browsers prior to the official standardization of specifications in order to diffuse their candidate proposals. Opera released its browser (Opera 9), which was partially compatible with Web Application 1.0 and Web Forms 2.0 in July 2006. Apple implemented CANVAS (a part 
of Web Application 1.0) in its web browser Safari. CANVAS and client storage were also implemented by the Mozilla Firefox 1.5. Furthermore, Google cooperated and supported Mozilla and Opera while it developed Gears as its own web application. Collectively, these collaborative networks promoted the diffusion of HTML5 among stakeholders, allowing them to realize the benefits of HTML5 for web services, browsers, and business models.

\subsection{Engaging Developer Communities}

Google's alliances with web browser vendors were not sufficient to gain extensive support for the process of standard setting at W3C and encourage web content developers to implement its proposed functions. Google successfully developed a policy to support HTML5 and key browser vendors and provided incentives for software engineers to utilize the HTML5 while increasing Google's reputation among software engineers. Thus, Google fostered two communities: a community for HTML5 standard development and a community for implementing HTML5 for web applications.

The structure of open digital platforms for web applications can be considered as a two-sided market. Platform owners need to attract both suppliers (i.e., developers of web applications) and consumers (i.e., users of web applications). It is critically important for platform owners to attract not only consumers but also suppliers in order to grow and sustain their platforms. In addition, the standardization process management policy used by the $\mathrm{W} 3 \mathrm{C}$ is an implementation-oriented policy. This means that no specification is certified as an industry standard unless more than two cases are implemented. The working groups and members of W3C sought to implement proposed specifications in the middle of the standard-setting processes. In addition, the HTML working group has adopted a policy that opens every stage of this standardization process to the public. Therefore, specifications can be improved based on feedback received from implementations developed by non-WG members. Accordingly, the supporters of HTML5 had to increase the number of implementation cases by engineers outside the standard-setting organization to gain a competitive advantage over XHTML. Hence, Google started supporting two types of developer communities: specification development communities and implementing communities.

Google supported WHATWG to promote standard development communities. WHATWG was established by Ian Hickson with the help of Apple, Mozilla, and Opera after the rejection of Hickson's proposal at the workshop. The WHATWG has aimed and continues to develop specifications for web applications primarily outside the W3C. Thus, Hickson started to create a draft titled "Web Applications Markup Language 1.0". This draft was then renamed "Web Application 1.0" and incorporated Web Forms 2.0 into HTML5. Thereafter, HTML5 included specifications for HTML with advanced form functions, multiple APIs and backward compatibility with existing versions of HTML. In other words, it became a deliverable of open collaboration in the innovation community [43]. WHATWG defined itself as "a growing community of people" rather than a joint venture of companies. The activities of WHATWG were open, so anyone could participate in and contribute to HTML5 development. Individuals can register to the working group easily, send messages to the listservs, and measure differences between multiple versions of specifications. WHATWG is organized as an open-source software project.

Furthermore, Google encouraged independent software engineers to establish and develop implementing communities. Platform owners had established communities to share information on some of their products. Moreover, most programming languages (e.g., Java of Sun Microsystems and net of Microsoft) were initially designed to promote firms' proprietary products or services. However, Google launched activities to support the developers of open standard technologies. Thus, Google promoted its technologies, APIs, and products for developers through face-to-face events, websites and other channels. Naoki Ishihara, an engineer of Google Japan and a previous Sun Japan employee, launched the "API Expert Program" with Kazuhiko Nishimura and Masahiko Yokota, a marketing outsourcing contractor. Google continues to value engineers working outside of the firm as API experts and provides technical information as needed. Furthermore, API experts 
are still expected to establish and manage unofficial users' communities to share technical information on Google. Thus, for example, Google began to hold monthly meetings with API experts at Google Japan headquarters. Nishimura explained that the end goal of the API Expert Program was to create ecosystems of Google's technologies and to foster key persons who utilize technologies to develop various types of applications. A marketer who worked with Nishimura said the following.

We tried to make as many engineers use Google's technologies as possible and encouraged them to post blog entries about their technologies.

[An executive of Abidarma, Inc.]

Engineers working outside Google developed technical information for sustainable diffusion and were loyal to the specifications and the company. To disseminate technological information and to manage engineering communities at no cost, API experts were expected to act as advisors and specialists in specific technological fields. Meanwhile, appointees could gain merit by creating good publicity and building a network of connections. A few appointees even published books. Thus, Google extended its program from the use of proprietary technologies to the use of open standards. As one HTML5 API expert stated:

I have obtained knowhow on managing grassroots engineering communities at meetings of API Experts. I think that Google and I obtain a mutual benefit, and therefore my employer allows me to participate in this program. I feel that I have contributed to my employer through this program.

[An engineer of NTT Communications]

The Google API Expert Program was established by its staff in Japan and was later adopted globally. Such activities were referred to as "developer relation programs", and more programs and events that featured HTML5 were held. This increased the number of supporters of HTML5. Google, therefore, not only promoted HTML5 but also encouraged outside developers to promote it and develop implementation cases. At this point, the W3C had already accepted the proposal for HTML5, and the standardization process had been integrated with the activity of the WHATWG. In short, Google and its peers' promotion of HTML5 made the specification popular among website developers.

Microsoft, a major web browser vendor that never participated in WHATWG activity, joined the HTML working group at the W3C in April 2007. Most major browser vendors and web application providers were already engaged in HTML5 standardization. However, Microsoft did not implement HTML5 into Internet Explorer. In contrast, Microsoft had developed and promoted a proprietary platform technology for multimedia content called Silverlight, which worked only with the Windows OS. Thus, website developers were irritated with Microsoft because Microsoft did not implement HTML5 in its products but instead promoted a proprietary technology with a vertically integrated architecture. The reason for this disapproval was that the website developers would have to create two types of websites: those for HTML5-compatible browsers and those for Internet Explorer. Furthermore, the cost of developing Internet Explorer-compatible websites was higher than those using HTML5. Therefore, the website developers launched a negative campaign against Internet Explorer: "IE6 Must Die." They displayed graphical figures signifying their protest using Internet Explorer 6 on the icons of their Twitter account. Thus, Microsoft was forced to adopt and implement HTML5. When Microsoft changed its strategy, Steve Ballmer, CEO of Microsoft, announced that the firm would treat HTML5 as one of Microsoft's core cross-platform technologies at the "Professional Developers Conference 2010".

With the work that we're doing with Internet Explorer, we're trying to make that a whole lot simpler for you. With Internet Explorer 9, we made our focus on a couple of things: No. 1, doing HTML5-standards-based HTML5-really, really, really well. And No. 2, asking the question: How do we improve on the user experience for HTML5 applications based upon the fact that we know Internet Explorer runs on Windows? [44] 
Microsoft released Internet Explorer 9 immediately prior to Ballmer's keynote speech and promoted it as a highly HTML5-compatible product. Since then, HTML5 has been implemented by all major web browsers.

\section{Discussion}

This study investigates how Google develops its strategies of building consensus and favourable market structure for the standard development and diffusion of HTML5. This paper conducts a comprehensive analysis of Google's strategic actions and the reactions of various stakeholders, including proponents, opponents and unaffiliated users, as well as the interactions among them. It sheds lights on the key roles of two strategic initiatives (i.e., integrating outside technologies and avoiding the monetization of technologies) and two relational practices (forming alliances with browser vendors and engaging developer communities) in the process of Google's development and the diffusion periods of HTML5. Google attracted web content developers and browser vendors to collaboratively develop HTML5 specifications and HTML5-compatible products and services, which favour for Google's business model based on open web application technology. These relational practices were enabled and amplified by Google's non-commercial initiatives to benefit conforming web applications and by its use of other parties' technologies.

These two strategic initiatives and relational practices can influence the mutual entanglement of standard development and diffusion. Although prior research addresses the importance of mutual relationships between standard development and diffusion, it has focused only on the standard setting process itself and lack a sole evaluation of firms' strategic actions $[8,15]$. Figure 1 illustrates the mechanisms behind Google's standardization strategies. A strategic initiative of integrating outside technologies reduces technology development costs and complements the technical expertise of Google; this initiative promoted HTML5 standard development. In addition, a relational practice of forming alliances with browser vendors reduces competition and coordination costs among stakeholders in a standard developing organization (the W3C in this case). This initiative and practice can collectively drive a standard development process, as Google demonstrated. While the literature points out the important roles of coordination and social aspects in standard development [7,22], it has not fully explored how to reach a consensus about the suitable specification for standards. Accordingly, the present study identifies the specific actions (integrating outside technologies and forming alliances) that facilitate cooperation in standard development.

Regarding the standard diffusion process, preceding research has identified several key factors to facilitate standard diffusion, such as a network effect [10], interoperability [12], and switching cost [11]. However, little is known about how firms enhance these factors while concurrently collaborating and competing in their industry. Therefore, this study investigates a strategic initiative and the relational practices used to accomplish it. Google promoted a strategic initiative to avoid the monetization of technologies. This initiative expedites standard diffusion through reducing costs for complementors' standard adoption and in the network effects among standard adopters. Moreover, Google's two relational practices also impacted the standard diffusion process. That is, alliances with other browser vendors enhance compatibility and corporation, which accelerate the diffusion of standards. Google's efforts to engage developer communities played a key role in establishing and sustaining web application developer communities that focus on HTML5 specifications. Thus, this practice facilitates standard diffusion by increasing the switching costs for application developers and the network effects among developers. The previous study has argued in favour of a formal activities to form a consensus by consortia or governments to facilitate standard diffusion [14,29]. However, this study sheds light on the importance of informal collaboration (community development) in IT standardization. Moreover, while software developer satisfaction and engagement improve the quality of web projects [45], the engagement of developer communities also contributes to the diffusion of standardized specifications. These strategic initiatives and relational practices shape the process of 
standardization; in the case of HTML5, they entailed the mutual constitutions of standard development and diffusion.

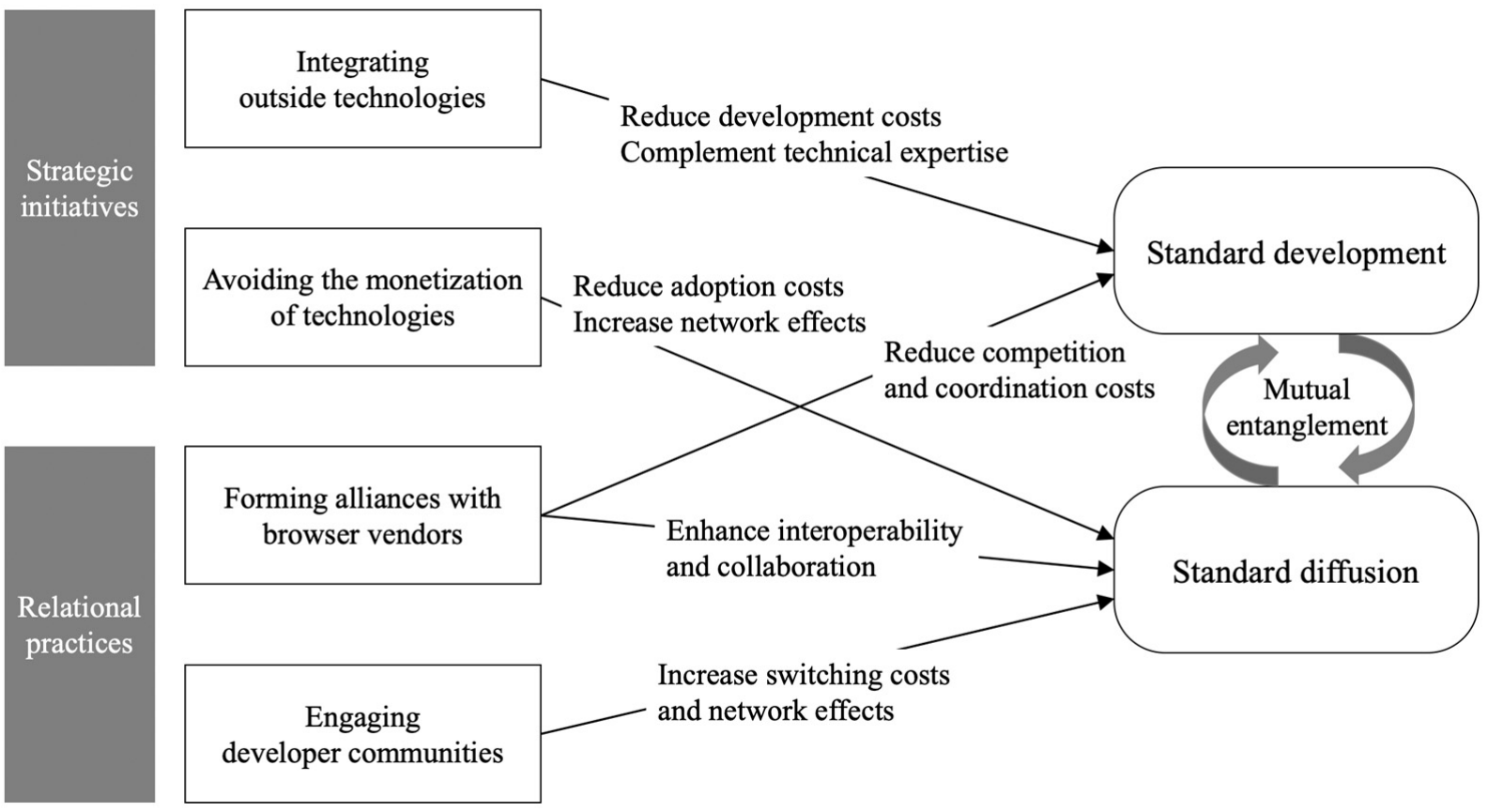

Figure 1. Mechanisms behind Google's standard development and diffusion strategies.

\section{Conclusions}

We examined strategic ways to encourage the development and diffusion of technological standards that align with a firm's innovation trajectories with forming a consensus with diverse stakeholders including competitors. The study shows two strategic initiatives (integrating outside technologies and avoiding the monetization of technologies) and two relational practices (forming alliances with browser vendors and engaging developer communities) employed by Google to realize open web application strategy with HTML5 standardization. We also discuss the potential mechanisms behind Google's standardization strategies for its innovation. Thus, this study addresses the intertwined mechanisms of IT standard development and diffusion and firm's strategic standardization practices, which have not been effectively investigated in the literature.

The study contributes to the literature on information systems and IT standardization in two ways. First, it extracts some key strategic initiatives and relational practices to lead a standard-setting process, which involves standard development and diffusion. The analysis articulates strategic firm activities that can shape IT standards in a favourable manner, even in industries with competing actors; for example, in the case of a hybrid (committee- and market-based) standardization [1]. Second, the paper highlights the importance of engagement for community development in a standard setting process. The previous research has clarified the role of formal coordination by consortia or governments in facilitating standard development and diffusion [14,29], but this study sheds light on the importance of informal collaboration (community development) in a hybrid standard setting. Contributions to and collaborations with communities have been critically important for innovation. Thus, fostering standard development and learning communities can help firms cooperatively develop and diffuse beneficial industry standards.

This study also has practical implications for managers. First, forming an alliance with competitors is helpful for (nondominant) firms to break the status quo of a dominant player in their industry. In the case of the standardization of HTML5, Google worked closely with Mozilla, Apple, and Opera to compete with Microsoft dominating the web browser market with Internet Explorer at that time. This cooperation enabled Google to develop the 
HTML5 specifications, standardise it collaboratively in its favour, and diffuse them among other key companies without difficulty. Then, this study articulates the critical role of community development in the development and diffusion of IT standards by firms. Since industry-wide standards require a consensus among diversified stakeholders in each field, to design standards in a supportive manner a firm needs to form a coalition with those stakeholders with similar interests who share the same vision and technological trajectories. To form an alliance, it is imperative to raise and support developer communities, which include both the specification and application developers. In particular, the standard setting process depends on how well a firm can manage and support such communities to be sustainable. Third, a firm should adopt strategic initiatives to promote these relational practices. For example, Google adopted a non-monetization strategy and technologies that had been invented outside its organization. This openness facilitated and supported its relational practices and has enabled successful standard development and diffusion.

Although this research provides the theoretical contributions and practical implications mentioned above, it also has some limitations that should be addressed in future research. It especially focuses on the case of HTML5 (IT standard) and Google's (a game changer in the web platform industry) strategic practices. We should be mindful of the boundary conditions (analytical transferability) of our findings. The more IoT and AI diffuse with data sharing through the Internet, the more services work in coordination among multiple devices and services with interactions based on technological standards, such as HTML5. Moreover, many products and services in traditional industries, such as manufacturing business and the energy industries, have developed and adopted industry standards to share data and provide services through the internet. Therefore, future studies need to examine how our findings are impacted by other backgrounds (e.g., non-IT standards) and to focus on other players in an industry (e.g., a dominant player). Furthermore, it might be useful to highlight the competition aspect of this standard-setting procedure. While this study partly addresses this point, future research could evaluate Microsoft's strategy and its countermeasures to Google's actions in more remarkable ways to clarify the dynamics of such competitive actions. Finally, we believe that innovating through standardization is becoming more important in business ecosystems in the IoT era and can serve as a promising research agenda for the fields of information systems and information science.

Author Contributions: Initial conceptualization, Y.F.; Theory development, Y.F. and T.S.; Data collection, Y.F.; Data analysis, Y.F. and T.S. Writing and revising, Y.F. and T.S. Visualization, T.S. All authors have read and agreed to the published version of the manuscript.

Funding: This study was supported by the Japan Society for the Promotion of Science KAKENHI 19K23235, 20H02384, and 20K13599.

Institutional Review Board Statement: This study was conducted according to the guidelines of Keio University.

Informed Consent Statement: Informed consent was obtained from all subjects involved in the study.

Data Availability Statement: Some public data will be made available upon the request to the authors.

Conflicts of Interest: There is no conflict of interest regarding this study.

\section{References}

1. Wiegmann, P.M.; de Vries, H.J.; Blind, K. Multi-Mode Standardisation: A Critical Review and a Research Agenda. Res. Policy 2017, 46, 1370-1386. [CrossRef]

2. Garud, R.; Kumaraswamy, A. Changing Competitive Dynamics in Network Industries: An Exploration of Sun Microsystems' Open Systems Strategy. Strateg. Manag. J. 1993, 14, 351-369. [CrossRef]

3. Blind, K.; Petersen, S.S.; Riillo, C.A.F. The Impact of Standards and Regulation on Innovation in Uncertain Markets. Res. Policy 2017, 46, 249-264. [CrossRef]

4. Aggarwal, N.; Dai, Q.; Walden, E.A. The More, the Merrier? How the Number of Partners in a Standard-Setting Initiative Affects Shareholder's Risk and Return. MIS Q. 2011, 35, 445-462. [CrossRef] 
5. Fukami, Y.; Shimizu, T. Innovating through standardization: How Google leverages the value of open digital platforms. In Proceedings of the Twenty-Second Pacific Asia Conference on Information Systems, Yokohama, Japan, 29 June 2018; pp. $2273-2285$.

6. Garud, R.; Jain, S.; Kumaraswamy, A. Institutional Entrepreneurship in the Sponsorship of Common Technological Standards: The Case of Sun Microsystems and Java. Acad. Manag. J. 2002, 45, 196-214.

7. Backhouse, J.; Hsu, C.W.; Silva, L. Circuits of Power in Creating de Jure Standards: Shaping an International Information Systems Security Standard. MIS Q. 2006, 30, 413-438. [CrossRef]

8. Markus, M.L.; Steinfield, C.W.; Wigand, R.T. Industry-Wide Information Systems Standardization as Collective Action: The Case of the U.S. Residential Mortgage Industry. MIS Q. 2006, 30, 439-465. [CrossRef]

9. Nickerson, J.V.; zur Muehlen, M. The Ecology of Standards Processes: Insights from Internet Standard Making. MIS Q. 2006, 30, 467-488. [CrossRef]

10. Kauffman, R.J.; McAndrews, J.; Wang, Y.M. Opening the "Black Box" of Network Externalities in Network Adoption. Inf. Syst. Res. 2000, 11, 61-82. [CrossRef]

11. Zhu, K.; Kraemer, K.L.; Gurbaxani, V.; Xu, S.X. Migration To Open-Standard Interorganizational Systems: Network Effects, Switching Costs, and Path Dependency. MIS Q. 2006, 30, 515-539. [CrossRef]

12. Bala, H.; Venkatesh, V. Assimilation of Interorganizational Business Process Standards. Inf. Syst. Res. 2007, 18, 340-362. [CrossRef]

13. Hovav, A.; Patnayakuni, R.; Schuff, D. A Model of Internet Standards Adoption: The Case of IPv6. Inf. Syst. J. 2004, 14, 265-294. [CrossRef]

14. Weitzel, T.; Beimborn, D.; Koenig, W. A Unified Economic Model of Standard Diffusion: The Impact of Standardization Cost, Network Effects, and Network Topology. MIS Quartely 2006, 30, 489-514. [CrossRef]

15. Botzem, S.; Dobusch, L. Standardization Cycles: A Process Perspective on the Formation and Diffusion of Transnational Standards. Organ. Stud. 2012, 33, 737-762. [CrossRef]

16. Uotila, J.; Keil, T.; Maula, M. Supply-Side Network Effects and the Development of Information Technology Standards. MIS Quartely 2017, 41, 1207-1226. [CrossRef]

17. Wen, J.; Qualls, W.J.; Zeng, D. Standardization Alliance Networks, Standard-Setting Influence, and New Product Outcomes. J. Prod. Innov. Manag. 2020, 37, 138-157. [CrossRef]

18. Gutiérrez, R.T. Understanding the Role of Digital Commons in the Web; The Making of HTML5. Telemat. Inform. 2018, 35, 1438-1449. [CrossRef]

19. Schrock, A.R. HTML5 and Openness in Mobile Platforms. Continuum 2014, 28, 820-834. [CrossRef]

20. Geels, F.W. From Sectoral Systems of Innovation to Socio-Technical Systems: Insights about Dynamics and Change from Sociology and Institutional Theory. Res. Policy 2004, 33, 897-920. [CrossRef]

21. David, P.A.; Greenstein, S. The Economics Of Compatibility Standards: An Introduction To Recent Research. Econ. Innov. New Technol. 1990, 1, 3-41. [CrossRef]

22. Simcoe, T. Standard Setting Committees: Consensus Governance for Shared Technology Platforms. Am. Econ. Rev. 2012, 102, 305-336. [CrossRef]

23. Lyytinen, K.; King, J.L. Standard Making: A Critical Research Frontier for Information Systems Research. MIS Q. 2006, 30, 405-411. [CrossRef]

24. Hanseth, O.; Jacucci, E.; Grisot, M.; Aanestad, M. Reflexive Standardization: Side Effects and Complexity in Standard Making. MIS Q. 2006, 30, 563-581. [CrossRef]

25. Zhao, K.; Xia, M.; Shaw, M.J. What Motivates Firms to Contribute to Consortium-Based E-Business Standardization? J. Manag. Inf. Syst. 2011, 28, 305-334. [CrossRef]

26. Axelrod, R.; Mitchell, W.; Thomas, R.E.; Bennett, D.S.; Bruderer, E. Coalition Formation in Standard-Setting Alliances. Manag. Sci. 1995, 41, 1493-1508. [CrossRef]

27. Leiponen, A.E. Competing Through Cooperation: The Organization of Standard Setting in Wireless Telecommunications. Manag. Sci. 2008, 54, 1904-1919. [CrossRef]

28. Katz, M.L.; Shapiro, C. Technology Adoption in the Presence of Network Externalities. J. Polit. Econ. 1986, 94, 822-841. [CrossRef]

29. Lee, H.; Oh, S. A Standards War Waged by a Developing Country: Understanding International Standard Setting from the Actor-Network Perspective. J. Strateg. Inf. Syst. 2006, 15, 177-195. [CrossRef]

30. Zhao, K.; Xia, M.; Shaw, M. An Integrated Model of Consortium-Based E-Business Standardization: Collaborative Development and Adoption with Network Externalities. J. Manag. Inf. Syst. 2007, 23, 247-271. [CrossRef]

31. Hanseth, O.; Bygstad, B. Flexible Generification: ICT Standardization Strategies and Service Innovation in Health Care. Eur. J. Inf. Syst. 2015, 24, 645-663. [CrossRef]

32. Langley, A. Strategies for Theorizing from Process Data. Acad. Manag. Rev. 1999, 24, 691-710. [CrossRef]

33. Yin, R.K. Case study research: Design and methods. In Applied Social Research Methods Series; Bickman, L., Rog, D.J., Eds.; Sage Publications: Los Angeles, CA, USA, 2009; Volume 5.

34. Lakhani, K.R.; Panetta, J.A. The Principles of Distributed Innovation. Innov. Technol. Gov. Glob. 2007, 2, 97-112. [CrossRef]

35. Brandenburger, A.M.; Nalebuff, B.J. Co-Opetition; Doubleday Business: New York, NY, USA, 1996.

36. Casadesus-Masanell, R.; Yoffie, D.B. Wintel: Cooperation and Conflict. Manag. Sci. 2007, 53, 584-598. [CrossRef]

37. Tsai, C.; Chen, M.L.; Marchak, M. Google Developers Blog: Google I/O 2009-Day 1 Recap. Available online: https://developers, googleblog.com/2009/05/google-io-2009-day-1-recap.html (accessed on 26 September 2021). 
38. Dutton, S. Chrome Dev Summit: Open Web Platform Summary. Available online: https://developers.google.com/web/updates/ 2014/01/Chrome-Dev-Summit-Open-Web-Platform-Summary (accessed on 26 September 2021).

39. Boodman, A. HTML5, Brought to You by Gears. Available online: https://sites.google.com/site/io/html5-brought-to-you-bygears (accessed on 31 January 2018).

40. Hachman, M. Google Gears Is Dead; Long Live HTML 5.0. Available online: http://www.pcmag.com/article2/0,2817,2356492, 00.asp (accessed on 31 January 2018).

41. Boodman, A. Stopping the Gears. Available online: http://gearsblog.blogspot.jp/2011/03/stopping-gears.html (accessed on 31 January 2018).

42. Mozilla; Opera. Position Paper for the W3C Workshop on Web Applications and Compound Documents. Available online: https:/ / www.w3.org/2004/04/webapps-cdf-ws/papers/opera.html (accessed on 31 January 2018).

43. Lynn, L.H.; Reddy, N.M.; Aram, J.D. Linking Technology and Institutions: The Innovation Community Framework. Res. Policy 1996, 25, 91-106. [CrossRef]

44. Ballmer, S. Steve Ballmer: PDC10 (Record of Keynote at Professional Developers Conference 2010). Available online: http: / / news.microsoft.com/2010/10/28/steve-ballmer-pdc10/ (accessed on 31 January 2018).

45. Fedushko, S.; Ustyianovych, T.; Syerov, Y.; Peracek, T. User-Engagement Score and SLIs/SLOs/SLAs Measurements Correlation of e-Business Projects through Big Data Analysis. Appl. Sci. 2020, 10, 9112. [CrossRef] 